\title{
Explosive shock and laser exposure of metallic and ceramic materials
}

\author{
O. T. Inal, P. F. Gerity \& D. H. Lopez \\ New Mexico Institute of Mining and Technology, USA
}

\begin{abstract}
Explosive shock and Q-switched laser exposure of metallic and ceramic materials have produced varied substructures and increased hardness that possibly emphasize the role of the attendant material structures and the nature of the defect substructures that are subsequently obtained. In metallic materials, Q-switched laser exposure is seen to result in extensive heating as well as shock wave passage effect, while the control of temperature in explosive detonation is seen to introduce shock effect and associated defect substructure. For example, explosive shock exposure of Al-Li 8090 alloy is seen to increase hardness, reduce activation energy for subsequent ageing, introduce precipitation, revealing the extensive role defect substructure plays in the ageing kinetics of this alloy. Shock loading of Molydenum at $150 \mathrm{kbar}$ (for $2 \mu \mathrm{s}$ ) increases dislocation loop densities from $5 \times 10^{9} / \mathrm{cm}^{3}$ to $4 \times 10^{14} / \mathrm{cm}^{3}$ with $75 \%$ of the loop types analyzed being vacancy loops. Irradiations utilizing a Q-switched laser at also of Mo at fluences between 22 and $35 \mathrm{~J} / \mathrm{cm}^{2}$ produced residual effects ranging from increasing numbers of lattice vacancies and vacancy clusters to massive deformation, cavitation, and spallation along with melting. Finally, explosive shock exposure, at various calculated pressures, of $\mathrm{Al}_{2} \mathrm{O}_{3}, \mathrm{Al}_{2} \mathrm{O}_{3}+\mathrm{ZrO}_{2}$, $\mathrm{Al}_{2} \mathrm{O}_{3}+\mathrm{SiC}$ (whisker), $\mathrm{Al}_{2} \mathrm{O}_{3}+\mathrm{ZrO}_{2}+\mathrm{SiC}$ (whisker), showed no significant difference in mechanical properties of hot-pressed $\mathrm{Al}_{2} \mathrm{O}_{3}+\mathrm{ZrO}_{2}$ composites with regard to shock treatment. Improved mechanical properties were occasionally found in shock-treated and hot-pressed whisker-reinforced alumina, although a direct relationship with shock pressure was not observed.

The manuscript summarizes these different studies in delineating the role of shock waves passage in the subsequent material processing. This is an overview of these research projects and fuller details can be found in the cited references.
\end{abstract}




\section{Laser and shock exposure of metallic materials}

Essentially, all laser interactions with metals involve the absorption of all or a portion of the light energy and its conversion to heat with or without a change in phase of the surface material. For radiation from Q-switched lasers, the interaction with metals has been considerable in terms of the surface rising to the vaporization temperature and vaporization being initiated. As materials recoil against the surface, high-pressure stress waves (or shock waves) can be generated. This pressure pulse raises the boiling point of the underlying material which becomes superheated as more heat is conducted into the interior. In effect, the thermal expansion which follows the rapid absorption of radiant energy at the surface of an elastic solid can propagate a shock wave into the interior. An important feature which distinguishes Q-switched laser interaction from that of a CW laser is the extremely large temperature gradients and the time rates of change of temperature $\left(>10^{9} \mathrm{C} / \mathrm{s}\right)$ involved. Since the production of stress waves in solids using high-powered pulsed lasers is fundamentally a surface phenomenon, the magnitude of those stress waves can be modified by modifications in the target surface conditions.

Laser-shock effects should be expected to be fundamentally different from those produced by plane shock waves generated by explosively driven flyer plates and the like because the laser generated shock waves will propagate from a small source region, the impinging laser beam spot, creating a radially attenuating stress pulse, while in conventional shock-loading case, the material is considered to be characterized by a uni-axial strain state which in most instances is not large and allows for a hydrostatic stress approximation [1].

\subsection{Experimental}

Annealed molybdenum and tungsten samples were irradiated, utilizing a Qswitched laser at fluences between 22 and $35 \mathrm{~J} / \mathrm{cm}^{2}$, in-situ in a field ion microscope. Irradiation produced residual effects ranging from increasing number of lattice vacancies and vacancy clusters to massive deformation, cavitation and spallation, and melting. The results of increasing vacancy concentration with increasing laser fluence for molybdenum and tungsten were compared to similar observations in explosively shock-loaded molybdenum in concluding that laser shocking can produce residual effects similar to those of approximately up to several hundred kbar peak pressure. Laser irradiation of electron transparent foils also confirmed the attendant features of laser irradiation including vaporization, melting, and shock-induced spallation by direct observation in the transmission electron microscope. Dislocation substructures identical to those observed following explosive-shock loading of molybdenum were also observed in the laser-irradiated molybdenum foils [1]. Additionally, molybdenum samples shock loaded to pressures of 150 and $250 \mathrm{kbar}$ at a constant pulse duration of $2 \mu$ s showed dislocation loop densities to increase from the annealed value of $5 \times 10^{9}$ to $4 \times 10^{14}$ and $7 \times 10^{14} / \mathrm{cm}^{2}$ respectively. Electron microscopy showed that $75 \%$ of the loops at $150 \mathrm{kbar}$ and $80 \%$ of the 
loops at 250 kbar were vacancy type. Increase in dislocation density was determined to be $1.0 \times 10^{10}$ to $1.2 \times 10^{10} / \mathrm{cm}^{2}$ between 150 and $250 \mathrm{kbar}$ for a concomitant increase in average residual microhardness form 514 to $770 \mathrm{~kg} / \mathrm{cm}^{2}$ in the same pressure range, revealing that shock induced vacancies contribute significantly to residual shock hardening $[2,3]$.

\subsection{Results}

From the experiments summarized herein [1-3] we observed that explosive shock exposure of metallic materials seem to result in the generation of excessive vacancies, in the form of mono vacancies, small aggregates and loops while laser exposure of these materials exhibit extensive heating along with a similar shock effect. The combined effects of laser irradiation resulted in various sections in melting and shock-induced spallation as well.

\section{Explosive shock exposure of Al-8090 alloy}

The structure and mechanical properties of Al-Li 8090 alloy, that was dynamically deformed and then age hardened, were studied as a function of the changes in the nature and amount of precipitates produced following exposure to various pulse durations of the shock waves. The study made a comparison between two groups of samples, one solution heat treated and quenched from $530^{\circ} \mathrm{C}$, previous to dynamic deformation and the other was exposed to shock deformation in the as received condition [4].

The precipitation temperatures for GP zones and $\delta^{\prime}\left(\mathrm{Al}_{3} \mathrm{Li}\right)$ are increased by the increased cold work state of the as received samples previous to shock treatment while precipitation of the $\mathrm{S}\left(\mathrm{Al}_{2} \mathrm{CuMg}\right)$ does not seem to be affected by the extent of previous cold work. The precipitation temperature for $\mathrm{S}\left(\mathrm{Al}_{2} \mathrm{CuMg}\right)$ phase, on the other hand, is seen to decrease with shock treatment and is an advantage since lower aging temperature for the Al-Li 8090 alloy avoids the emergence of the $\delta(\mathrm{AlLi})$ phase; the presence of precipitate free zones (PFZ) at the high and low angle grain boundaries that ensues leads to strain localization [5]. Increased pulse duration is seen to decrease the time to peak age and increased hardness at the lower aging temperatures $\left(165\right.$ and $\left.180^{\circ} \mathrm{C}\right)$ but produces no effect at the higher $\left(197^{\circ} \mathrm{C}\right)$ one. The activation energies calculated suggest two processes to be occurring: annealing, $\mathrm{Q}_{1}$, and precipitation, $\mathrm{Q}_{2}$. $\mathrm{Q}_{1}$ increases but $\mathrm{Q}_{2}$ decreases as cold work is increased in the material, when aging is performed in the low temperature range. Solution heat treated and shocked samples show minimum tensile elongation and maximum yield strength when peak aged at $165^{\circ} \mathrm{C}$, suggesting the emergence of the $\mathrm{S}\left(\mathrm{Al}_{2} \mathrm{CuMg}\right)$ phase leading to planar slip. As received and shocked samples show a constant $6 \%$ maximum tensile elongation for all aging temperatures. Peak yield strength values are produced at $180^{\circ} \mathrm{C}$, suggesting that $\mathrm{S}\left(\mathrm{Al}_{2} \mathrm{CuMg}\right)$ phase emergence is retarded because of the extra deformation. Finally, an increase in pulse duration increases yield strength and UTS in both the as received and the shock treated 
samples alluding to the role of the increased defect substructure to the precipitation process [4].

\subsection{Experimental}

The study tried to elucidate the roles of explosive shock introduced defects on the precipitation kinetics of ageing in the Al-Li 8090 alloy. Two sets of samples, one as received (extruded) and the other solution heat treated at $530^{\circ} \mathrm{C}$ for 1 hour and quenched, were exposed to shock pressures of one, two and three layers of Dupont Data sheet C-1; the thickness changes were assumed to correspond to a commensurate increase in the pulse duration of the shock wave [6].

Subsequent DSC scrutiny showed that $165^{\circ} \mathrm{C}$ corresponded to the emergence of the GP zones, 180 and $197^{\circ} \mathrm{C}$ for the precipitation of the $\delta{ }^{\prime}\left(\mathrm{Al}_{3} \mathrm{Li}\right)$ and $260^{\circ} \mathrm{C}$ for the appearance of the $\mathrm{S}\left(\mathrm{Al}_{2} \mathrm{CuMg}\right)$ phase. The subsequent hardness versus time studies revealed the different trends in hardness values achieved with different ageing temperatures and were also used in the enumeration of the associated activation energies.

\subsection{Results}

In terms of the aging kinetics observed, it is seen that the precipitation of the $\delta^{\prime}\left(\mathrm{Al}_{3} \mathrm{Li}\right)$ takes place at $150^{\circ} \mathrm{C}$ for the solution heat treated sample and at $190^{\circ} \mathrm{C}$ in the as received sample. Following shock treatment the solution heat treated sample exhibits a value of $180^{\circ} \mathrm{C}$ while the as received and shocked sample precipitates the $\delta$ ' phase at $197^{\circ} \mathrm{C}$. In both cases, the increased pulse duration does not seem to alter the temperature of emergence of the phase; i.e. shortest pulse duration was sufficient in magnitude for the creation of a uniform defect substructure throughout the sample cross-section as also verified by the uniformity of the micro hardness measurements throughout the cross-sections.

In looking at the DSC data, the solution heat treated samples sequence of precipitation are $111^{\circ} \mathrm{C}$ for $\mathrm{GP}$ zones, $150^{\circ} \mathrm{C}$ for $\delta^{\prime}\left(\mathrm{Al}_{3} \mathrm{Li}\right)$ and $263^{\circ} \mathrm{C}$ for $\mathrm{S}\left(\mathrm{Al}_{2} \mathrm{CuMg}\right)$ while the corresponding shocked values are $116^{\circ} \mathrm{C}$ for $\mathrm{GP}$ zones, $180^{\circ} \mathrm{C}$ for $\delta^{\prime}\left(\mathrm{Al}_{3} \mathrm{Li}\right)$ and $258^{\circ} \mathrm{C}$ for $\mathrm{S}\left(\mathrm{Al}_{2} \mathrm{CuMg}\right)$. For the as received samples, on the other hand, $158^{\circ} \mathrm{C}$ for $\mathrm{GP}$ zones, $190^{\circ} \mathrm{C}$ for $\delta^{\prime}\left(\mathrm{Al}_{3} \mathrm{Li}\right)$ and $264^{\circ} \mathrm{C}$ for $\mathrm{S}\left(\mathrm{Al}_{2} \mathrm{Cu}\right.$ $\mathrm{Mg})$ and the corresponding shocked values are $165^{\circ} \mathrm{C}$ for $\mathrm{GP}$ zones, $197^{\circ} \mathrm{C}$ for $\delta^{\prime}\left(\mathrm{Al}_{3} \mathrm{Li}\right)$ and $258^{\circ} \mathrm{C}$ for $\mathrm{S}\left(\mathrm{Al}_{2} \mathrm{CuMg}\right)$ phase; i.e. the extent of defect substructure plays a very prominent role in the ageing process. While higher temperatures are required for the precipitation of GP zones and $\delta$ ' $\left(\mathrm{Al}_{3} \mathrm{Li}\right)$ phase, this increases with the initial extent of deformation. This is totally reversed in the emergence of the $\mathrm{S}\left(\mathrm{Al}_{2} \mathrm{CuMg}\right)$ phase. Such a reduction of the precipitation temperature for the $\mathrm{S}\left(\mathrm{Al}_{2} \mathrm{CuMg}\right)$ phase is quite beneficial from the processing point of view, as indicated earlier. Reduced aging temperature reduces the chance for the formation of the $\delta(\mathrm{AlLi})$ phase in the peak-aged and over-aged conditions and thus obviates the formation of PFZ zones.

The fact that increased pulse duration did not influence precipitation temperature at all indicates that the defect substructure created was saturated 
with the lowest pulse duration and thus increase in the time of passage of shock waves did not alter this substructure at least for the benefit of the ageing treatment (it did affect the Y.S. and UTS values as was stated earlier).

\section{Properties of shock-treated and subsequently sintered compacts}

To see the effects of "shock activation" in sintering processes, $\mathrm{Al}_{2} \mathrm{O}_{3}$ and $\mathrm{ZrO}_{2}$ and/or $\mathrm{SiC}_{\mathrm{w}}$ (whisker)containing compacts were exposed to calculated [7] shock pressures of 4,7 , and $10 \mathrm{GPa}$ previous to sintering at the appropriate temperatures [8].

The effects of shock treatment and consolidation method on densification behavior and mechanical properties of $\mathrm{Al}_{2} \mathrm{O}_{3}, \mathrm{Al}_{2} \mathrm{O}_{3}+\mathrm{ZrO}_{2}, \mathrm{Al}_{2} \mathrm{O}_{3}+\mathrm{SiC}$ (whisker), and $\mathrm{Al}_{2} \mathrm{O}_{3}+\mathrm{ZrO}_{2}+\mathrm{SiC}$ (whisker) were studied. It was established that shock treatment does not improve the sintering kinetics of alumina or alumina-based composites. On the other hand, partial shock compaction followed by sintering provided higher densities compared to sintering alone. Unshocked and pressureless sintered materials possessed better mechanical properties than shock-treated materials, in general. No significant difference was noted in the mechanical properties of hot-pressed $\mathrm{Al}_{2} \mathrm{O}_{3}+\mathrm{ZrO}_{2}$ composites with regard to shock treatment. Improved mechanical properties were occasionally found in shock-treated and hot-pressed whisker-reinforced alumina, although a direct relationship with shock pressure was not observed. This improvement was attributed to decreased whisker aspect ratios upon shock treatment, leading to improved microstructural uniformity [8].

The above results are not surprising since shock treated materials are seen to be very resistant to post-shock heat treatment [9]. Although this is believed to emanate from the excessive defect sub-structure created by the shock exposure, an actual study of its origin has not been made to date. In addition, explosive welding produced metal tandems and explosive consolidation produced rods are also seen to be resistant to post-shock heat treatment. Examples of this stability was observed in the $\mathrm{TiAl}_{3}$ intermetallic, consolidated from atomized powders, wherein the dendritic features of the atomized powder was seen to be retained following post-shock heat treatment at $850^{\circ} \mathrm{C}$ for four hours. Also explosively welded Al-Steel tandems showed no diffusion created artifacts following heat treatment at $550^{\circ} \mathrm{C}$ for 8 hours [9].

\subsection{Experimental}

The above shock treatments of powders and/or powder mixtures were made in powder compaction fixtures designed to consolidate the included powders. These are axisymmetric assemblies wherein the powders are held in a tubular container surrounded by the explosive. Detonation of the explosive causes a shock wave to travel down the length of the container; the kinetic energy imparted to the powder by the shrinking tube producing the consolidation of the powder. Generally, an explosive with low detonation velocity (ANFO; $V_{D} \cong 3400$ 
$\mathrm{m} / \mathrm{s})(7)$ is used to avoid cracking, especially in ceramic powder consolidation, of the composite due to application of such high pressures.

The uniformity of microhardness data on consolidated cross-sections and the absence of mach-stem in the center of consolidated rods seem to both indicate that the shock exposure throughout the compaction canisters were uniform.

\subsection{Results}

Shock treatment of $\mathrm{Al}_{2} \mathrm{O}_{3}$ or $\mathrm{Al}_{2} \mathrm{O}_{3}+\mathrm{ZrO}_{2}$ powders do not seem to provide activated sintering. We found no, significant, difference in hot-pressed densities of these composites upon shock-treatment, compared to unshocked counterparts.

Shock-compacted and sintered pellets of alumina and alumina-based composites attained higher fractional densities compared to their cold-pressed and sintered counterparts. This is attributed to the higher initial densities of shock-compacted samples. The disadvantage of explosive compaction, though, is the crack formation during any of the compaction, recovery, or sintering stages.

\section{Concluding remarks}

L.E. Murr [10], in his summary of extensive shock loading experiments scrutinized through transmission electron microscopy, shows that shock-induced microstructures are determined primarily by the stacking fault energy of the host lattice. High stacking-fault energy metals and alloys are characterized by dislocation cell structures while low stacking-fault energy metals and alloys (with predominantly face centered cubic structures) are characterized by planar dislocation arrays, stacking faults and twins in $\{111\}$ planes. High stacking-fault energy metals and alloys also exhibit twinning.

Likewise, Clauer et al. [11] show that pressure pulses, generated by pulsed laser exposure on the surface of metal and propagating into it, in the form of shock waves, produce changes in the materials' microstructure and properties similar to those of shock waves produced through other means. In depth microstructural and property changes produced is initially formulated through calculations of pressure pulse and its amplitude and then observed to be in the form of increases in hardness, tensile strength and fatigue life. The last affect appears to result from the significant residual surface stresses introduced by the shock process.

It is thus obvious that both processing are means of introducing hardening into materials through microstructural changes produced in the form of defects and their aggregates and are very useful as final processing rather than as an additive for advantage to a classical manufacturing process. Explosive consolidation, welding and forming [9, 12] have been successfully utilized along with shock hardening of railway components [12]. Our attempts in "shock activation" previous to sintering has been less than successful [8] although gains in the energetics of the ageing process in the Al-Li alloy could be considered a success as well. 


\section{References}

[1] Inal, O.T. and Murr, L.E. Laser-Shock Induced Microstructural Changes and a Comparison with Explosive-Shock-Induced Phenomena in Metals: Field-Ion and Electron Microscopic Studies. Journal of Applied Physics, 28(4) pp. 2427-2434, 1978.

[2] Murr, L.E.; Inal, O.T. and Morales, A.A. Vacancies and Vacancy Clusters in Shock-Loaded Molybdenum: Direct Observation by Transmission Electron and Field-Ion Microscopy. Applied Physics Letters, 28(8) pp. 432-434, 1976.

[3] Murr, L.E.; Inal, O.T. and Morales, A.A. Direct Observations of Vacancies and Vacancy-Type Defects in Molybdenum Following Uniaxial Shockwave Compression. Acta Metallurgica, 24(3) pp. 261-270, 1976.

[4] Esquivel, R. and Inal, O.T. Characterization of Shock-Hardened Al-8090 Alloy. Journal of Materials Science, 30(22) pp. 5825-5832, 1995.

[5] Ashton, R.F.; Thompson, D.S.; Starke, E.A. and Lin, F.S. Processing AlLi-Cu-(Mg) Alloys. Aluminum-Lithium Alloys III, Eds. C. Baker, P.J. Gregson, S.J. Harris and C.J. Peel, The Institute of Metals, London, pp. 66-77, 1986.

[6] Starke, E.A.; Sanders, T.H. and Palmer, I.G. New Approaches to Alloy Development in The Al-Li System. Journal of Metals, 33(8) pp. 24-33, 1981.

[7] Wang, S.L. Explosive Consolidation of Nickel-Base Superalloy Powders. Ph.D. Thesis, New Mexico Institute of Mining and Technology, Socorro, New Mexico, 1986.

[8] Bengisu, M. and Inal, O.T. Sintering of $\mathrm{MgO}$ and $\mathrm{MgO}-\mathrm{TiC}$ Ceramics by Plasma, Microwave and Conventional Heating. Journal of Materials Science, 29(20), pp. 4824-4833, 1994.

[9] Inal, O.T. and Zimmerly, C.A. Processing of Materials with Explosives. In the Proceedings of the International Metallurgy and Materias Congress, Vol. 1, Eds. E.S. Kayali, M. Urgen, K. Sesen, C.H. Gur and L. Ovecoglu, Chamber of Metallurgical Engineers, Ankara, Turkey, pp. 751-764, 1997.

[10] Murr, L.E. Residual Microstructure-Mechanical Property Relationships in Shock-Loaded Metals and Alloys. In Shock Waves and High Strain Rate Phenomena in Metals. Eds. M.A. Meyers and L.E. Murr, Plenum Press, N.Y. pp. 607-673, 1980.

[11] Clauer, A.H.; Holbrook, J.H. and Fairland, B.P. Effects of Laser-Induced Shock Waves on Metals. In Shock Waves and High Strain Rate Phenomena in Metals. Eds. M.A. Meyers and L.E. Murr, Plenum Press, N.Y.pp. 675-702, 1980.

[12] Deribas, A.A. Explosive Metalworking in the U.S.S.R. In Shock Waves and High Strain Rate Phenomena in Metals. Eds. M.A. Meyers and L.E. Murr, Plenum Press, N.Y. pp. 915-940, 1980. 